\section{U New Device N6 (Un6): Avoid Lumbar Instability after Lumbar Discectomy}

\author{
Iñaki Arrotegui* \\ Department of Neurosurgery, Hospital General Universitario de Valencia, \\ Spain
}

\begin{abstract}
Introduction: The authors conducted a prospective study in patients with disc herniation. We compared the results obtained in patients treated with the New "U" device N6 (UN6) with those acquired in patients treated without any device. The UN6 implant is a titanium alloy device that is placed between the spinous processes (L5-S1).

Method: A cohort of 50 patients with degenerative lumbar disc, 25 who underwent surgical treatment in which the UN6 device was placed and 25 control individuals who were treated with discectomy alone. Patients underwent serial follow-up evaluations and radiographic assessment was used to determine the outcome. Up to two years of follow-up (2013-2014) data were obtained for all patients.

Results: A statistically significant improvement was seen in patients treated with the UN6 for the management of lumbar disc degeneration and to avoid lumbar instability in the future, $85 \%$ vs $70 \%(p<0.01)$, and the use of the new design at L5-S1 in relation to other existing devices on the market would be $90 \%$ vs $60 \%$.

Conclusion: Our study shows that the UN6 was more effective than the discectomy group in the management of lumbar instability. In addition, we are able to perform the UN6 insert in almost all cases (90\%).

Keywords: Degenerative lumbar disc; Interspinous device; Lumbar instability; Lumbar spine surgery; Lumbar spinous process; Microdiscectomy
\end{abstract}

\section{Introduction}

Interspinous spacers/stabilizers are implants which are introduced between the spinous processes of the lumbar spine to achieve some segmental distraction and/or to unload the facet joints.

The behaviour of a functional spinal unit is related to the displacement of the centre of rotation, making it possible to balance

*Corresponding author: Iñaki Arrotegui, Department of Neurosurgery, Hospital General Universitario de Valencia, Avda Tres Cruces S/n: 46014-Valencia Spain, Tel: +34 627492961; E-mail: athbio@yahoo.es

Citation: Arrotegui I (2015) U New Device N6 (Un6): Avoid Lumbar Instability after Lumbar Discectomy. J Orthop Res Physiother 1: 013.

Received: April 01, 2015; Accepted: September 16, 2015; Published: September 30, 2015 the moments and thus control the transferred loads. When a lordotic posture is used, the downward transmission of forces results in redistribution of loads which tend to be transferred posteriorly to the facet joints. The facet joints have both an absorbing and stabilizing role. Their impairment results from an on-going aging process.

This UN6 implant is a titanium device that is inserted between the spinous processes. The new UN6 implant is an interlaminar/interspinous stabilizer designed to assist the degenerated segment in both flexion and extension by means of its novel dynamic ability to stretch and compress in synchronization with the normal movement of the functional spinal unit.

There are different types of $U$ device on the market, none of which allows the device to be used in all cases at the L5-S1 level, given that the size of the "U" does not adapt to the anatomy of S1, especially in women.

\section{Indications}

\section{Disc herniation}

This indication mainly applies for the L4/L5 level due to the anatomical size of the spinous process of L4 and L5. The device is used to prevent pain resulting from overloading of the facets following a discectomy. Image analysis and intra operative observation are most important because they may reveal hypertrophy of the posterior facets, synovial cyst and stretching of the posterior supraspinous ligament with abnormal approximation of the spinous process.

It is important to note that the consequences of the posterior transfer of loads are evidenced by indirect signs which need to be identified. These include retrolisthesis, discal hyperlordosis and disc tilt (often clearly visible with the patient under general anaesthesia in prone position).

The posterior interspinous stabilizer restores the vertical component of the posterior moment arm, which helps re-establish ligamentotaxis.

\section{Precautions}

In osteoporotic bone, it is important to properly position the implant which must rest on the junction between the spinous process and the lamina. Stable degenerative spondylolisthesis (grade I): this borderline indication is a matter of surgical experience.

\section{Contraindications}

- Unstable spondylolisthesis

- Neoplasia

- Fracture

- Isthmic spondylolysis

- Idiopathic scoliosis

This is a minimally invasive procedure which does not involve neural structures directly. A specific complication may be a dislocation of the implant and lack of effectiveness. 


\section{Anatomical Considerations}

The new implant is a functionally dynamic device. To the extent that, should we disrupt the normal segmental musculature, we would damage the inherent dynamic stabilization of the spine, which would have a negative influence on our surgical outcome. The implant conforms to the interspinous anatomy and allows it to be placed with minimal disturbance to the segmental muscles. While a simple midline approach with dissection of muscles from the spinous process is possible, attention to the details of segmental anatomy can preserve the neuromuscular integrity of the back.

There are three anatomical diagnoses (with a possible combination of two or all of them): foraminal stenosis, soft stenosis (disco-ligamentous) and kissing spines. The implant acts on the foraminal bony elements to change local conditions (reducing venous congestion and traction on the spinal ganglion).

\section{Surgical Technique}

It is important the position in which you place the patient: this should be in slight de lordosis. Neither should the " $U$ " extend to the interspinous space. When you insert the implant in place, you should fit snugly. The rounded part of it should be maintained at $5 \mathrm{~mm}$ from the sheath of the dura. The pins prevent the implant from being inserted into the channel, and the lordosis prevents it from moving backwards while the implant remains under load. The two thin and malleable legs fit around the spinous process, blocking the rotation.

\section{Objective}

We compared up to two years outcomes between patients with post-discectomy and the new UN6 device versus patients who underwent surgery alone. Our goal was to assess the clinical outcome of patients with lumbar disc degeneration before and at periodic intervals after implantation of the UN6 device. We also wanted to evaluate the mechanisms of the action and effectiveness of interspinous distraction in managing symptomatic lumbar disc herniation to determine the safety and efficacy of the new implant and to avoid disc degeneration as described by White \& Panjabi and Kirkaldy-Willis [1].

\section{Summary of Background Data}

The interlaminar/ interspinous implant is an interspinous implant designed for patients with symptomatic spinal stenosis particularly lumbar/moderate neurogenic claudication, but we can carry out a prospective double blind control trial in order to discover whether we can avoid or delay the last step of disc lumbar surgery namely lumbar instability.

\section{Method}

50 patients (all diagnosed with lumbar disc herniation) were enrolled and 25 of them were surgically treated with the new implant. The UN6 device was implanted at the end of disc surgery in each patient. They were clinically and radiographically (Figures 1 and 2) evaluated at the pre-operative stage, 3 and 6 months later and finally 1-2 years from the intervention using clinical questionnaires.

\section{Inclusion criteria}

The patients were adults scheduled to undergo their first surgery for the removal of a unilateral, herniated, lumbar, intervertebral disc associated with radiculopathy. Specific inclusion criteria required signs and symptoms of lumbar or lumbosacral radiculopathy predominantly affecting one nerve root level, radiologic evidence of nerve root compression (MRI), and/or confirmed the existence of an extruded or sequestered disc fragment at L5-S1 compatible with clinical signs and symptoms.

The patients included in the study underwent at least 6 weeks of nonoperative treatment without resolution of pain. During the 6-week nonoperative period, the physician treated the patient as necessary with physical therapy, narcotics, or any other non-disqualifying treatments that would alleviate the patient's discomfort. No patient had epidural steroid treatment withheld to qualify for the study.

The study was designed as a prospective comparison of two treatments given to patients who had undergone spinal surgery (lumbar disc surgery) and was conducted by the investigators at a single site.
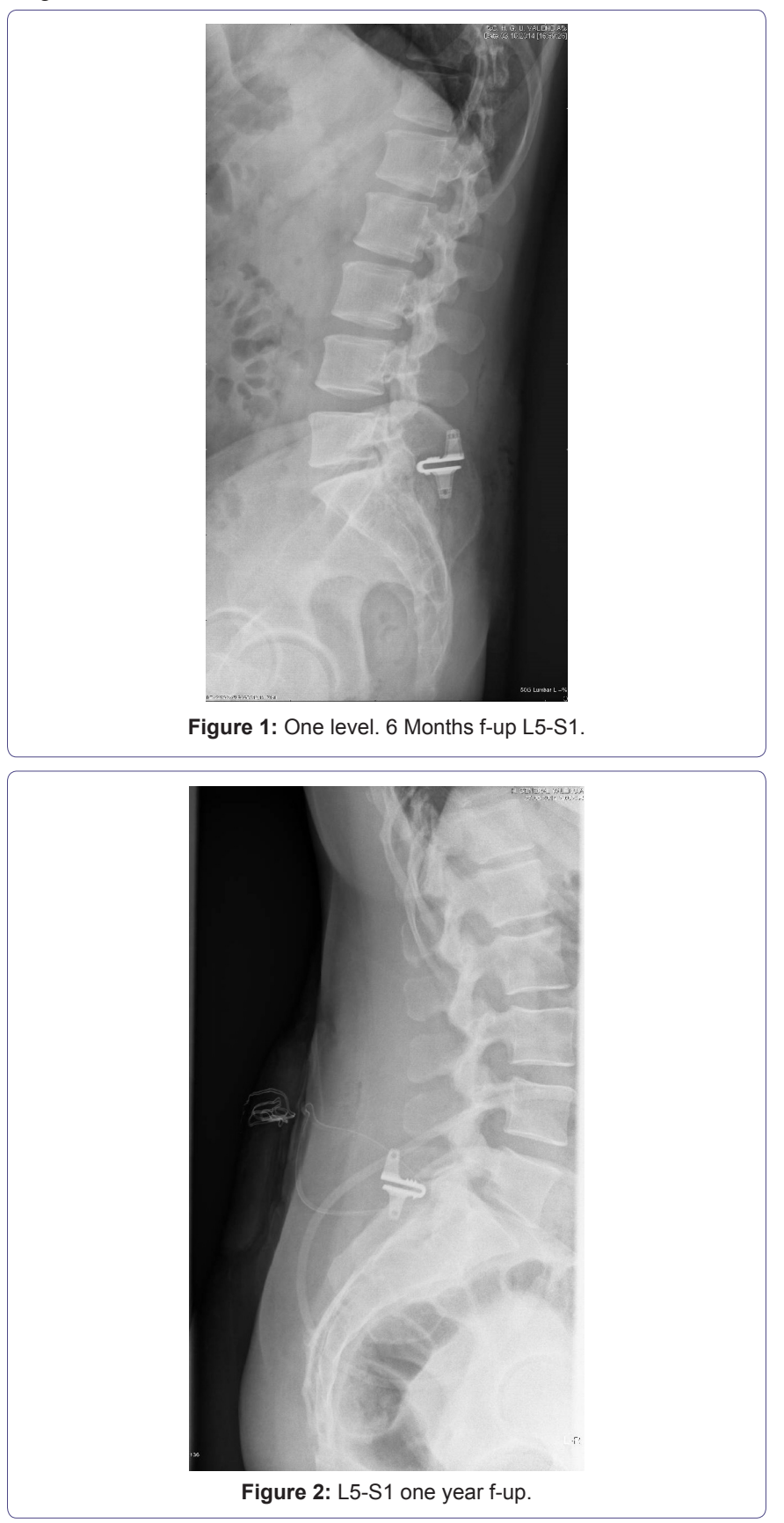


\section{Ethics}

Patients were treated according to good clinical practice and signed informed consent for all surgical procedure, thus fulfilling the requirements of the 1996 revised version of the Helsinki Declaration. Valencia general hospital (Spain) gave permission for the documental review and clinical questionnaire to be carried out by independent specialists. Ethical number 018/2013.

A self-assessment questionnaire (lumbar spine outcomes questionnaire) related to patients' pain, symptoms, was completed before surgery and at scheduled postoperative intervals (30 days, 90 days, 6 to 24 months etc.).

A computer-generated paradigm randomized patients to a treatment (UN6) or control (standard) group with balanced assignments across the study centre. Randomization occurred immediately before wound closure. The study patients were not informed as to their group assignment until after the data had been analysed.

All the patients were assessed by means of a physical examination, neurological function of their lower extremities, wound inspection and self-assessment LSOQ.

\section{Maintaining the study blinding}

The following procedures were used to maintain blinding for all ratings and assessments. The investigator, site study coordinator and other applicable site personnel agreed not to discuss the treatment assignments during the course of the study or to provide any documents to the patient that could reveal the assignment. The patient completed the self-assessment questionnaires before meeting with the physician or study coordinator.

Randomization was assigned when the patient's surgical procedure was completed to the point at which haemostasis was assured and the surgeon was ready to close the operative site. At that time, the sponsor was called for patient assignment: to receive UN6 or not to receive any device. All the patients underwent closure in the surgeon's routine fashion.

\section{Results}

50 patients underwent lumbar disc surgery (2013-2014)

- Control group (25 patients)

- UN6 group (25 patients)

- Total UN6 device (25 patients)

- One level (25 patients)

\section{- 2 years follow-up 25}

All patients who underwent placement of the UN6 implant at the level of L5-S1 (Figure 3) reported long-term improved symptoms. Our overall complications were due to two spinous process device infections, $1 \%$ of all surgery carried out since we performed this surgery in 2004 (200 patients). Our success rate is comparable with previously reported success rates. I have been developing this surgery since 2004, with different types of implants (Coflex's U-device, the "U"). When surgery was performed at L5-S1 and due to the anatomical configuration of S1, the possibility of placing the implant never exceeded $60 \%$, due to the anatomical spinous process of S1 and the device itself.

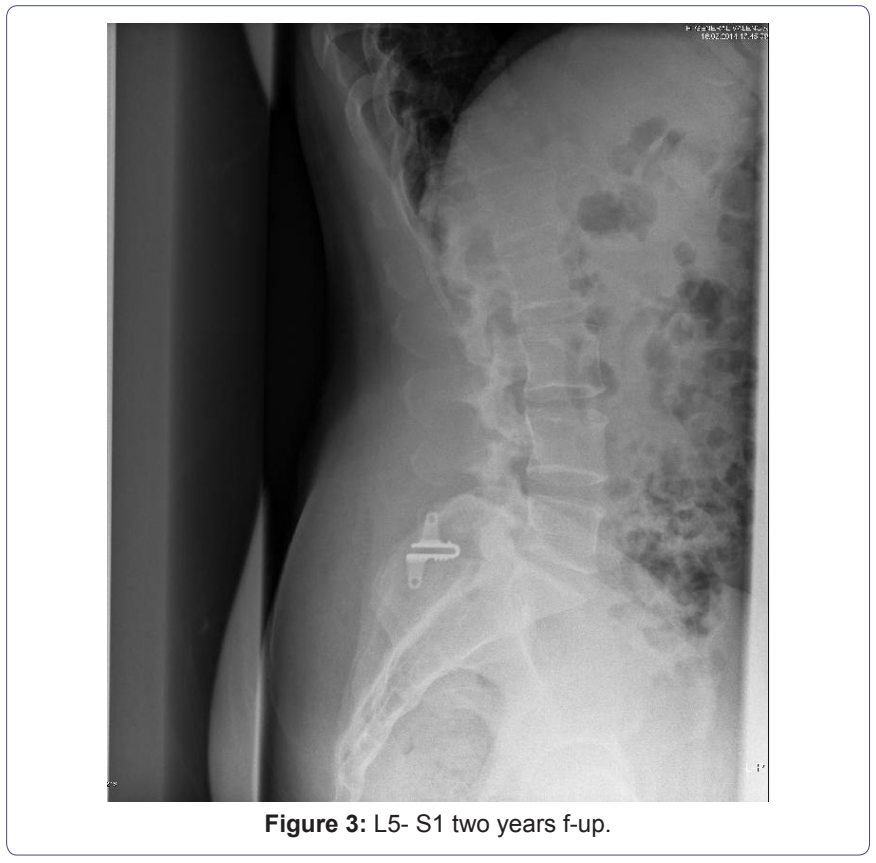

\section{Discussion}

The degeneration of the lumbar spine begins with the loss of intervertebral disc height, secondary to dehydration of the nucleus pulposus. This overloads the facet joints whose anatomy is not designed to bear weight thus leading to the development of spondyloarthritis and posterior hypertrophy [2,3]. Voltage loss and structural damage to the ligaments of the spine, which produce instability, also appear [4-6].

This instability is compensated due to hypertrophy of other structures like yellow ligament that eventually results in the narrowing of the canal and the foramina of conjunction.

The most common outcome of all this cascade of pathophysiological events is chronic low back pain, which is very disabling and has a difficult medical management $[7,8]$.

The conventional surgical treatment for chronic low back pain causes the fusion of degenerative spinal segment, thus irreversibly eliminating movement. However, despite the fact that the perfection of the technique has achieved fusion rates of $100 \%$, not comparable to clinical outcomes of pain relief have been obtained and, on the contrary, the possibility of developing disease in the adjacent segment means that alternative therapies $[9,10]$ are being sought.

The management of the lumbar spine without causing fusion and maintaining movement stems from this need. This dynamic stabilization theoretically would prevent disease in the adjacent segment, especially in young patients.

Multiple previous dynamic systems as well developed, trying to replace the intervertebral disc, based on experience with joint prosthetic hip and knee replacements. The problem of THA vertebral disc is replacing the former component of the motion segment, but not stabilized and requires facet joints without degeneration; therefore maintains the movement but does not stabilize, it is really wanted: to stabilize motion preservation.

The action mechanism of these systems is through the separation of the spinous processes between each vertebra the spinal canal increase. 
The management of the lumbar spine without causing fusion and maintaining movement stems from this need. This dynamic stabilization theoretically would prevent disease in the adjacent segment, especially in young patients.

Thus, multiple prior dynamic systems were also developed, in an attempt to replace the intervertebral disc, based on experience with joint prosthetic hip and knee replacements. The problem with the THA vertebral disc is that it replaces the anterior component of the motion segment, but does not stabilize and requires facet joints with no degeneration; it therefore maintains the movement but does not stabilize, which is what we really want: to stabilize while, at the same time, maintaining mobility.

The action mechanism of these systems is carried out by using the separation of the spinous processes between each vertebra to expand the spinal canal.

Recent biomechanical analyses have concluded that when one of these procedures is carried out, overlying segmental instability is generated over time, which is why the use of a semi-rigid interspinous spacer is recommended $[11,12]$.

We can then take into account that their indication is limited to the narrow spinal canal and lumbar facet disorders in lumbar segments between L3-L4-L5, with very limited indications in the lumbosacral transition (L5-S1) [13]. Since the development of this new device all that has changed, and constitutes the best find in our clinical study: to allow the placement of a device which prevents instability after Lumbar discectomy in almost all patients operated.

The degree of success of the use of the UN6 device in terms of reoperation rate and implant survival did not depend on the number of segments treated. This contrasts with the failure rate of lumbar fusion, which is reported to increase with the number of fused segments. The observed absence of a difference between the actuarial survivorship of single-level implants and multiple-level implants also supports the safety and efficacy of each segment of these multi-level dynamic constructs. Should there be any flaws inherent in the system, one would expect a poorer outcome in a series of double-level implants, not to mention that in patients with three or four instrumented levels. Moreover, the patients operated on two, three or four levels arguably had more advanced degenerative lesions than those operated on one level. The lack of difference between the outcomes of the two groups should be highlighted.

Despite limitations related to the high attrition rate, this first long-term analysis of an interspinous dynamic lumbar stabilization system provides promising information. The primary relevance of this study was that it demonstrated the long-term safety of the system.

The aim of the study was not to demonstrate the superiority of the device over fusion. The goal was to delay a relatively invasive fusion procedure for as long as possible (even definitively) with a simple superficial device that preserved the segmental anatomy $[14,15]$. By achieving this goal in around $80 \%$ of the patients for 7 years, the coflex implants demonstrated efficacy in delaying fusion (historical group 2004-2011) due to the fact that they presented no clinical symptoms or Rx signs.

When revision was necessary, there were no implant-related complications and the surgical procedure was quite straightforward. In terms of reoperation rates, the long-term outcomes of the UN6 implants indicate that they may be a valuable addition to our therapeutic armamentarium for degenerative lumbar segments, notably after decompressive procedures for certain cases of herniated disc occurring in segments with advanced changes and instability. With the endpoint 'any subsequent lumbar operation', the actuarial survivorship analysis compares favourably with that of revision operations adjacent to lumbar fusion procedures recently reported in the literature [16-19]. This might reflect long-term protective action against adjacent-level degeneration by motion preservation. More importantly, this was not a fusion procedure. Contrary to fusion, the vertebrae, discs, facet joints and ligaments except for the interspinous ligament were left intact and functional during surgery so that all therapeutic options remained open [20-22]. This is a safe device that can be used without great risk when a decompressive procedure is being carried out, thus possibly reducing the need for a further operation.

This semi-rigid device is appropriate for patients with severe low back pain (Baastrup syndrome) whose symptoms are exacerbated in extension and relieved in flexion, implanted between the spinous processes without disrupting the normal anatomical structures $[23,24]$.

Interspinous implants are used for motion-preserving stabilization of primarily posterior lumbar spinal pathologies like spinal stenosis or facet joint arthritis [25-27]. In the interspinous "U" device, the height of the same distracts the foraminal opening; the " $U$ " shape is designed to allow controlled movement in forward and backward bending [28-30]. This implant has only a transient effect on the postoperative restoration of disc height and reduction of slip in spondylolisthesis. This cannot be used as a substitute for a rigid fusion in cases of marked instability [31-33]. As we all know and, because of the anatomical characteristics of the space L5-S1, the chances of placing these implants is reduced by configuration of the same (size and design) because they do not adapt to the specific characteristics of the anatomical region [34-36]. The development and use of this UN6 device has allowed us to place it in $90 \%$ of the cases studied, by opening the anterior third of the vertebral body.

To date, monitoring by means of Rx (Figure 4) at 3-6 months and 1-2 years has allowed us to objectively observe the absence of any kind of movement of the device once put into place.

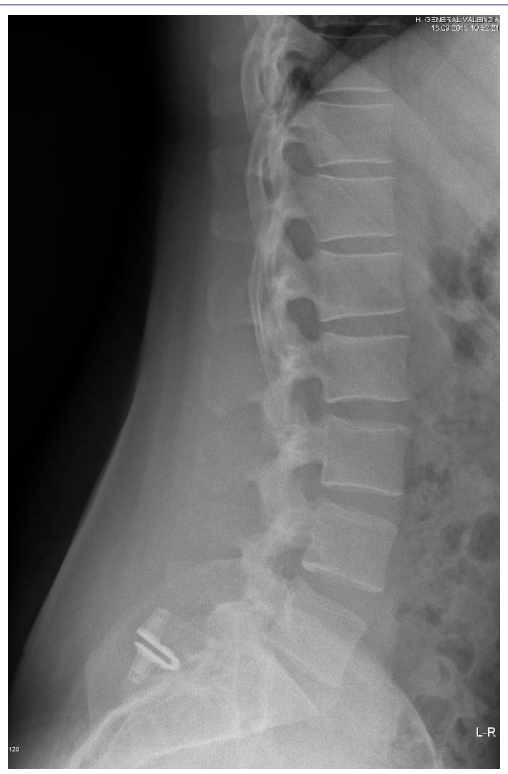

Figure 4: F-Up. 
Unlike other authors [37-39] who have started to use this technique for the treatment of stenosis and although our experience is also proven, we wanted to advance the possibilities of this spacer by using it in surgery for virgin herniated lumbar disc.

As we move forward towards our goal, we try to avoid a process of instability that requires more aggressive treatment (transpedicular fixation). We, of course, rely on the idea of the triad which determines that on occasion radiographic abnormalities are detected from a clinical point of view.

From the idiosyncrasies of our own study based on the arthritic degenerative process of human beings that can be exacerbated by the surgical technique to produce an overload segment and accelerate the osteoarthritic process and, although our study has a follow-up ranging from a maximum of 10 years to a minimum of 1 year (historical group 2004 to present), and, although preliminary data obtained allows us to be optimistic about the use of the implant to the delay of the instability of the segment after single discectomy. In relation to the use of the UN6 device, this has proved to be effective as has its versatility for segment L5-S1.

\section{Conclusion}

The ease of the learning curve at L5-S1 depends on the S1 spinous process, but the development of this new device has enabled us to place it in $90 \%$ cases. In order to better understand the long-term development after disc surgery and to prevent further degeneration, namely lumbar instability, a 7 years follow up was performed, with excellent results, historical group (2004-2011), but we believe that, as already mentioned an even longer follow-up is necessary as regard the monitoring of their placement in order to prevent or delay the appearance of the instability of the segment. We have a historical group with a 10 years follow up since 2004, with excellent results as regards the delay of lumbar instability.

\section{References}

1. Panjabi MM, Takata K, Goel VK (1983) Kinematics of lumbar intervertebral foramen. Spine (Phila Pa 1976) 8: 348-357.

2. Wiseman CM, Lindsey DP, Fredrick AD, Yerby SA (2005) The effect of an interspinous process implant on facet loading during extension. Spine (Phila Pa 1976) 30: 903-907.

3. Kettler A, Drumm J, Heuer F, Haeussler K, Mack C, et al. (2008) Can a modified interspinous spacer prevent instability in axial rotation and lateral bending? A biomechanical in vitro study resulting in a new idea. Clin Biomech (Bristol, Avon) 23: 242-247.

4. Christie SD, Song JK, Fessler RG (2005) Dynamic interspinous process technology. Spine (Phila Pa 1976) 30: 73-78.

5. Anderson PA, Tribus CB, Kitchel SH (2006) Treatment of neurogenic claudication by interspinous decompression: application of the X STOP device in patients with lumbar degenerative spondylolisthesis. J Neurosurg Spine 4: 463-471.

6. Zucherman JF, Hsu KY, Hartjen CA, Mehalic TF, Implicito DA, et al. (2005) A multicenter, prospective, randomized trial evaluating the $X$ STOP interspinous process decompression system for the treatment of neurogenic intermittent claudication: two-year follow-up results. Spine (Phila Pa 1976) 30: 1351-1358.

7. Floman $Y$, Millgram MA, Smorgick Y, Rand N, Ashkenazi E (2007) Failure of the Wallis interspinous implant to lower the incidence of recurrent lumbar disc herniations in patients undergoing primary disc excision. J Spinal Disord Tech 20: 337-341.
8. Verhoof OJ, Bron JL, Wapstra FH, van Royen BJ (2008) High failure rate of the interspinous distraction device (X-Stop) for the treatment of lumbar spinal stenosis caused by degenerative spondylolisthesis. Eur Spine J 17: 188-192.

9. Siddiqui M, Smith FW, Wardlaw D (2007) One-year results of X Stop interspinous implant for the treatment of lumbar spinal stenosis. Spine (Phila $\mathrm{Pa}$ 1976) 32: 1345-1348.

10. Lauryssen C (2007) Appropriate selection of patients with lumbar spinal stenosis for interspinous process decompression with the X STOP device. Neurosurg Focus 22: 5.

11. Chiu JC (2006) Interspinous Process Decompression (IPD) system (X-STOP) for the treatment of lumbar spinal stenosis. Surg Technol Int 15: 265-275.

12. Sénégas J (2002) Mechanical supplementation by non-rigid fixation in degenerative intervertebral lumbar segments: the Wallis system. Eur Spine J 11: $164-169$

13. Idler C, Zucherman JF, Yerby S, Hsu KY, Hannibal M, et al. (2008) A novel technique of intra-spinous process injection of PMMA to augment the strength of an inter-spinous process device such as the X STOP. Spine (Phila Pa 1976) 33: 452-456.

14. Talwar V, Lindsey DP, Fredrick A, Hsu KY, Zucherman JF, et al. (2006) Insertion loads of the X STOP interspinous process distraction system designed to treat neurogenic intermittent claudication. Eur Spine J 15: 908-912.

15. Kondrashov DG, Hannibal M, Hsu KY, Zucherman JF (2006) Interspinous process decompression with the X-STOP device for lumbar spinal stenosis: a 4-year follow-up study. J Spinal Disord Tech 19: 323-327.

16. Fuchs PD, Lindsey DP, Hsu KY, Zucherman JF, Yerby SA (2005) The use of an interspinous implant in conjunction with a graded facetectomy procedure. Spine (Phila Pa 1976) 30: 1266-1272.

17. Münnich U, König DP, Loch Ch, Heyll U (2007) [Interspinous decompression as treatment for lumbar spinal stenosis]. Versicherungsmedizin 59: 176-178.

18. Bellini CM, Galbusera F, Raimondi MT, Mineo GV, Brayda-Bruno M (2007) Biomechanics of the lumbar spine after dynamic stabilization. J Spinal Disord Tech 20: 423-429.

19. Lee J, Hida K, Seki T, Iwasaki Y, Minoru A (2004) An interspinous process distractor (X STOP) for lumbar spinal stenosis in elderly patients: preliminary experiences in 10 consecutive cases. J Spinal Disord Tech 17: 72-77.

20. Lindsey DP, Swanson KE, Fuchs P, Hsu KY, Zucherman JF, et al. (2003) The effects of an interspinous implant on the kinematics of the instrumented and adjacent levels in the lumbar spine. Spine (Phila Pa 1976) 28: 2192-2197.

21. Olmarker K (1991) Spinal nerve root compression. Nutrition and function of the porcine cauda equina compressed in vivo. Acta Orthop Scand Suppl 242: $1-27$.

22. Olmarker K, Holm S, Rosenqvist AL, Rydevik B (1991) Experimental nerve root compression. A model of acute, graded compression of the porcine cau$\mathrm{da}$ equina and an analysis of neural and vascular anatomy. Spine (Phila $\mathrm{Pa}$ 1976) 16: 61-69.

23. Postacchini $F$ (1996) Management of lumbar spinal stenosis. J Bone Joint Surg $\mathrm{Br}$ 78: 154-164.

24. Pratt RK, Fairbank JC, Virr A (2002) The reliability of the shuttle walking test, the swiss spinal stenosis questionnaire, the Oxford spinal stenosis score, and the oswestry disability index in the assessment of patients with lumbar spinal stenosis. Spine (Phila Pa 1976) 27: 84-91.

25. Ragab AA, Fye MA, Bohlman HH (2003) Surgery of the lumbar spine for spinal stenosis in 118 patients 70 years of age or older. Spine (Phila Pa 1976) 28: $348-353$

26. Rauschning W (1987) Normal and pathologic anatomy of the lumbar root canals. Spine (Phila Pa 1976) 12: 1008-1019.

27. Richards JC, Majumdar S, Lindsey DP, Beaupré GS, Yerby SA (2005) The treatment mechanism of an interspinous process implant for lumbar neurogenic intermittent claudication. Spine (Phila Pa 1976) 30: 744-749. 
28. Ridley MG, Kingsley GH, Gibson T, Grahame R (1988) Outpatient lumbar epidural corticosteroid injection in the management of sciatica. $\mathrm{Br} \mathrm{J}$ Rheumatol 27: 295-299.

29. Riew KD, Yin Y, Gilula L, Bridwell KH, Lenke LG, et al. (2000) The effect of nerve-root injections on the need for operative treatment of lumbar radicular pain. A prospective, randomized, controlled, double-blind study. J Bone Joint Surg Am 82: 1589-1593.

30. Rivest C, Katz JN, Ferrante FM, Jamison RN (1998) Effects of epidural steroid injection on pain due to lumbar spinal stenosis or herniated disks: a prospective study. Arthritis Care Res 11: 291-297.

31. Schönström N, Lindahl S, Willén J, Hansson T (1989) Dynamic changes in the dimensions of the lumbar spinal canal: an experimental study in vitro. J Orthop Res 7: 115-121.

32. Selby DK (1983) Conservative care of the lumbar spine in the elderly. Geriatrics 38: $42-50,55-56$
33. Stucki G, Daltroy L, Liang MH, Lipson SJ, Fossel AH, et al. (1996) Measurement properties of a self-administered outcome measure in lumbar spinal stenosis. Spine (Phila Pa 1976) 21: 796-803.

34. Stucki G, Liang MH, Fossel AH, Katz JN (1995) Relative responsiveness of condition-specific and generic health status measures in degenerative lumbar spinal stenosis. J Clin Epidemiol 48: 1369-1378.

35. Stucki G, Liang MH, Lipson SJ, Fossel AH, Katz JN (1994) Contribution of neuromuscular impairment to physical functional status in patients with lumbar spinal stenosis. J Rheumatol 21: 1338-1343.

36. Takahashi K, Kagechika K, Takino T, Matsui T, Miyazaki T, et al. (1995) Changes in epidural pressure during walking in patients with lumbar spinal stenosis. Spine (Phila Pa 1976) 20: 2746-2749.

37. Wiesel SW, Cuckler JM, Deluca F, Jones F, Zeide MS, et al. (1980) Acute low-back pain. An objective analysis of conservative therapy. Spine (Phila Pa 1976) 5: 324-330.

38. Yerby SA, Lindsey DP, Kreshak J (2001) Failure load of the lumbar spinous process. 47th annual meeting, Orthopaedic research society, San Francisco, CA, USA. 